\title{
Microbial production of sabinene-a new terpene-based precursor of advanced biofuel
}

\author{
Haibo Zhang ${ }^{1}$, Qiang Liu², Yujin Cao ${ }^{1}$, Xinjun Feng ${ }^{1}$, Yanning Zheng ${ }^{1}$, Huibin Zou', Hui Liu', Jianming Yang ${ }^{1 *}$ \\ and Mo Xian ${ }^{1 *}$
}

\begin{abstract}
Background: Sabinene, one kind of monoterpene, accumulated limitedly in natural organisms, is being explored as a potential component for the next generation of aircraft fuels. And demand for advanced fuels impels us to develop biosynthetic routes for the production of sabinene from renewable sugar.

Results: In this study, sabinene was significantly produced by assembling a biosynthetic pathway using the methylerythritol 4-phosphate (MEP) or heterologous mevalonate (MVA) pathway combining the GPP and sabinene synthase genes in an engineered Escherichia coli strain. Subsequently, the culture medium and process conditions were optimized to enhance sabinene production with a maximum titer of $82.18 \mathrm{mg} / \mathrm{L}$. Finally, the fed-batch fermentation of sabinene was evaluated using the optimized culture medium and process conditions, which reached a maximum concentration of $2.65 \mathrm{~g} / \mathrm{L}$ with an average productivity of $0.018 \mathrm{~g} \mathrm{~h}^{-1} \mathrm{~g}^{-1}$ dry cells, and the conversion efficiency of glycerol to sabinene (gram to gram) reached $3.49 \%$.

Conclusions: This is the first report of microbial synthesis of sabinene using an engineered E. coli strain with the renewable carbon source as feedstock. Therefore, a green and sustainable production strategy has been established for sabinene.
\end{abstract}

Keywords: Sabinene, Geranyl diphosphate synthase, Sabinene synthase, Escherichia coli

\section{Background}

Progresses in metabolic engineering and synthetic biology boost the engineering of microbes to produce advanced biofuels [1-3]. Among the bio-based fuels, terpenes, which are derived from the head-to-tail condensation of dimethylallyl pyrophosphate (DMAPP) and isopentenyl pyrophosphate (IPP), and traditionally used in flavorings, fragrances [4], medicines and fine chemicals [5,6], have the potentials to serve as advanced biofuel precursors [7-9].

Terpenes are a large and diverse class of organic compounds, which are mainly produced by a variety of plants. They are generated from the common precursors, IPP and DMAPP, which can be produced from the methylerythritol 4-phosphate (MEP) pathway or the mevalonate (MVA) pathway (Figure 1) [10]. Although many microorganisms harbor the MEP pathway or MVA pathway to supply the

\footnotetext{
*Correspondence: yangjm@qibebt.ac.cn; xianmo@qibebt.ac.cn ${ }^{1}$ CAS Key Laboratory of Biobased Materials, Qingdao Institute of Bioenergy and Bioprocess Technology, Chinese Academy of Sciences, No.189 Songling Road, Qingdao, Laoshan District 266101, China

Full list of author information is available at the end of the article
}

intermediates DMAPP and IPP, they are unable to produce the monoterpenes for the lack of monoterpenes synthases. With the rising demand for advanced fuels, terpene-based advance fuels attract more attentions. Many researchers explored microbial methods of monoterpene productions by introducing heterologous monoterpene synthase, including 3-carene, limonene, pinene and bisabolene. Reiling et al. engineered $E$. coli strain with overexpression native 1-deoxy-D-xylulose-5-phosphate synthase (DXS), farnesyl diphosphate synthase (IspA), IPP isomerase (IPIHp) from Haematococcus pluvialis, and 3-carene cyclase from Picea abies, which can accumulate a 3carene titer of about $3 \mu \mathrm{g} / \mathrm{L} / \mathrm{OD}_{600}$ after $8 \mathrm{~h}$ production [11]. Carter et al. constructed a monoterpene biosynthesis pathway in $E$. coli with a titer of about $5 \mathrm{mg} / \mathrm{L}$ limonene production using the native MEP pathway [12]. Bisabolene, $\alpha$-pinene et al. had been produced using MVA heterologous pathway in microorganisms $[9,13,14]$.

Sabinene (CAS: 3387-41-5), a perfume additive, is being explored as the components for the next generation 
aircraft fuel $[7,8]$. Meanwhile, sabinene contributes to the spiciness of black pepper, is a principal component of carrot seed oil, and occurs at a low concentration in tea tree oil. Currently, sabinene is extracted from plants, which is inefficient and requires substantial expenditure of natural resources because of the low content of them [15]. Though sabinene was found in the culture of an endophytic Phomopsis sp. as a component of its volatile organic compounds, further work need to be done for microbial production method because of the low tilter in the mixture [16]. Consequently, green and sustainable microbial technologies, which could engineer microorganisms to convert renewable resources from biomass to biobased advanced biofuels, provided an alternative strategy [17-19].

In this paper, sabinene was significantly produced by assembling a biosynthetic pathway using the MEP or heterologous MVA pathway combining the GPP and sabinene synthase genes in an engineered E. coli strain. Subsequently, the culture medium and process conditions were optimized to enhance sabinene production. Finally, fedbatch fermentation of sabinene was evaluated using the optimized culture medium and process conditions.

\section{Results and discussion}

\section{Characterization of sabinene by GC-MS}

E. coli cannot produce sabinene because of the absence of sabinene synthase, though it possesses a native MEP pathway which can supply the intermediates DMAPP and IPP (Figure 1). Consequently, sabinene synthase (SabS1) derived from Salvia pomifera was introduced into the E. coli strain (HB1), to synthesize sabinene. However, after $36 \mathrm{~h}$ of incubation of the modified strain, only trace of the target product could be detected by GC-MS (data not shown), based on the relative retention time and total ion mass spectral comparison with the external standard. The main reason might lie in the insufficiency of GPP in the host, because the wild $E$. coli seldom produces terpene. Hence, the native gene IspA from $E$. coli W3100, which encodes farnesyl diphosphate synthase, was added to enhance the metabolic flux into GPP by catalyzing the conversion of DMAPP and IPP. The gene IspA combining with the sabinene synthase gene (SabS1) was ligated into pACYCDuet-1 to create the plasmid pHB3 (pACY-IspA-SabS1). The E. coli strain harboring $\mathrm{pHB} 3$ was inoculated in the initial fermentation medium and incubated at $37^{\circ} \mathrm{C}$ with shaking at $180 \mathrm{rpm}$ in shake-flasks. IPTG was added to a final concentration of $0.5 \mathrm{mM}$ when its $\mathrm{OD}_{600}$ reached 0.6-0.9, and culture was further maintained at $37^{\circ} \mathrm{C}$ for $24 \mathrm{~h}$. The off-gas from the headspace of the sealed cultures was tested by GC-MS. The engineered E. coli BL21(DE3) strain harboring the native IspA gene and SabS1 from S. pomifera produced sabinene in detectable quantities (shown in Figure 2). Thus, using the MEP pathway and SabS1 from S. pomifera, the biosynthetic pathway for sabinene production was successfully constructed in E. coli BL21(DE3). The result also indicated that introduction of GPP synthase was beneficial to enhance the metabolic flux into GPP which would improve the sabinene products efficiently. 

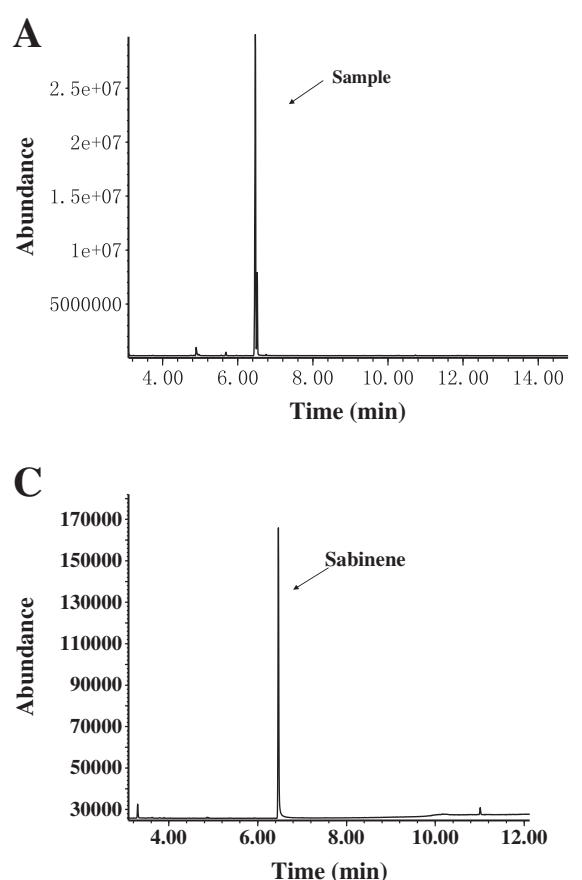

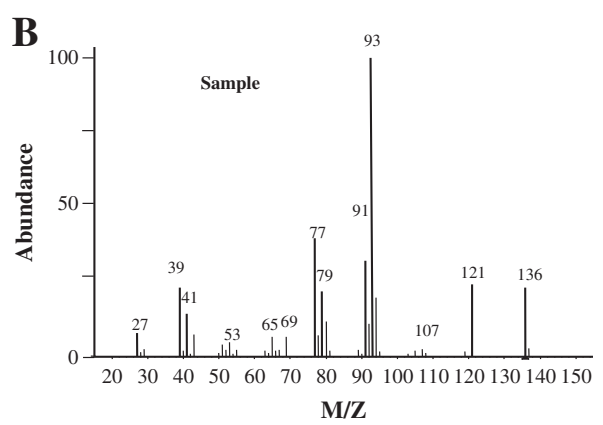

D

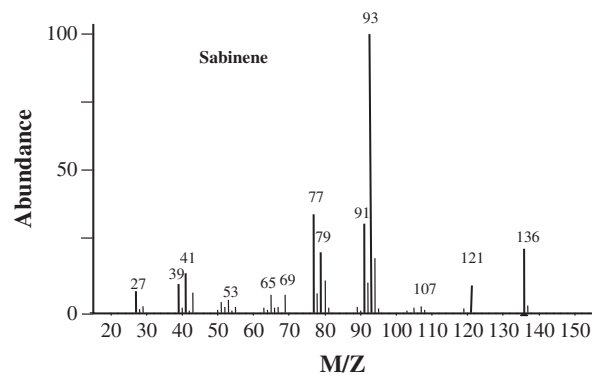

Figure $2 \mathrm{GC}-\mathrm{MS}$ analysis of sabinene from the headspace of the sealed cultures of strain $\mathrm{HB} 2$. Cultures were induced at $37^{\circ} \mathrm{C}, \mathrm{OD}_{600}=0.6-0.9$, and final concentration of 0.25 mM IPTG. By comparing with the authoritative sabinene (A, B), the capacities of sabinene biosynthesis were verified. A, C, total ion chromatogram (TIC); C, D, mass spectrum. Based on the relative retention time and total ion mass spectral comparison with an external standard, sabinene production was identified.

\section{Screening of GPP synthases}

GPP synthase, is one of the rate-limiting enzyme in the sabinene synthesis of E. coli BL21(DE3) [20]. An effective method to optimize pathway efficiency may be to use genes of rate-limiting enzymes from different organisms [21]. In this study, GPPS enzymes from Abies grandis (GPPS2) and E. coli were evaluated to enhance the supply of GPP.

The GPPS2 gene from $A$. grandis or IspA gene from E. coli was cloned into the plasmid pACYCDuet-1 along with the sabinene synthase gene $(S a b S 1)$ to create the plasmid pHB3 or pHB5, respectively, which were subsequently harbored by E. coli BL21(DE3) to screen the GPP synthase, because of the difficulty in detecting and quantifying GPP. The strains HB2 (harboring pHB3) and HB3 (harboring pHB5) were cultured in 600-ml shake-flasks with $100 \mathrm{ml}$ of fermentation medium. When each culture reached an $\mathrm{OD}_{600}$ of 0.6-0.9, expression of GPP synthase and sabinene synthase was induced by $0.25 \mathrm{mM}$ IPTG, and the culture was further incubated at $37^{\circ} \mathrm{C}$ for $24 \mathrm{~h}$. A noticeable difference in sabinene production was observed between the two strains. The strain HB3 produced $2.07 \mathrm{mg} / \mathrm{L}$ sabinene, while the strain $\mathrm{HB} 2$ produced $0.96 \mathrm{mg} / \mathrm{L}$ (Figure 3A). This result demonstrates that the exogenous expression of GPPS contributed to the sabinene production, and the enzyme activity of GPPS2 from $A$. grandis was higher than that of IspA from E. coli
W3100. IspA could give substantial amounts of the larger prenyl diphosphates, FPP and GGPP, in addition to GPP [22], that was why GPPS2 from $A$. grandis was more efficient than IspA in the synthesis of GPP. Hence, the GPPS2 was selected to enhance GPP production in the following experiments.

\section{Screening of synthetic pathways for sabinene production}

The hybrid exogenous MVA pathway is effective to synthesize DMAPP and IPP according to previous experimental data. The recombinant strain HB4 (E. coli harboring the MVA pathway, GPPS and sabinene synthase) and strain HB3 (E. coli harboring the native MEP pathway, GPPS synthase and sabinene synthase) were cultured to test the effect of the MVA pathway on the production of sabinene, in fermentation medium under shake-flask conditions. The sabinene titer of strain HB4 reached $44.74 \mathrm{mg} / \mathrm{L}$ after being induced by $0.25 \mathrm{mM}$ IPTG for $24 \mathrm{~h}$ with glycerol as carbon source and beef powder as nitrogen source (Figure $3 \mathrm{~B}$ ). The titer was about 20-fold higher than that of the strain HB3 cultured at the same conditions.

These results indicated that the hybrid MVA pathway caused a huge increase in sabinene production, which was accordant with the production of other terpenes using a hybrid exogenous MVA pathway in engineered $E$. coli strains [23]. One reason for the inefficiency of MEP approach was the regulatory mechanisms present in the 

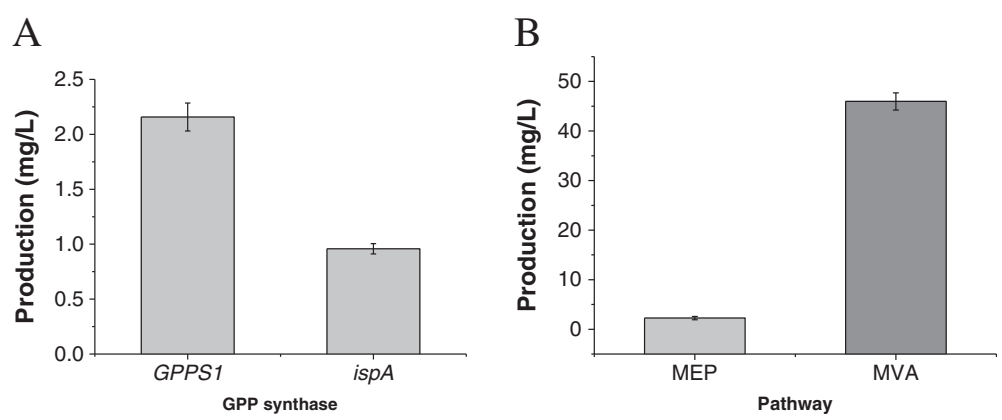

Figure 3 Effect of GPP synthase and metabolic pathway on sabinene production. A: Effect of GPP synthase. GPPS1, GPP synthase form A grandis; IspA, GPP synthase from E. coli. B: Effect of metabolic pathway on sabinene production, the pathway details were described in section Figure 1. The strain harboring GPPS2 can produce 2.2-fold higher concentration of sabinene than IspA, while the strain harboring MVA pathway can produce 20 -fold higher concentration of sabinene than MEP pathway.

native host [24]. This limitation was also confirmed by experiments on isoprene production using the MEP or MVA pathway [23,25]. It is because the hybrid exogenous MVA pathway is effective to synthesize DMAPP and IPP, which are the precursors of GPP. Consequently, we hypothesized that the engineered strain with the hybrid exogenous MVA pathway could further enhance the production of sabinene. Therefore, the strain HB4 harboring the hybrid exogenous MVA pathway was chosen for further experiments.

\section{Optimization of fermentation medium and culture conditions}

Fermentation medium and culture conditions play a vital role in the formation, concentration and yield of the end product [26], and they also provide data for fed-batch fermentation. Optimizing fermentation medium and culture conditions for strains can make the fed-batch fermentation easy to get higher quality and quantity products. In this study, the one-factor-at-a-time method, which is based on the classical method of changing one independent variable while fixing all others $[27,28]$, is applied to optimize medium components as well as process conditions. The four most important factors, carbon source, organic nitrogen source, induction temperature, and inducer concentration were optimized to improve sabinene production, using the strain HB4.

\section{Effect of organic nitrogen source on sabinene production}

The source of the nitrogen in the medium, especially the organic, which can also provide trace nutrition for micro-being, plays an important role in improving the biosynthesis of desired products [29]. Four different organic nitrogen sources were assessed to investigate the effect of organic nitrogen source on sabinene production (Figure 4A). Beef powder permitted a little higher sabinene production than other organic nitrogen sources, among the organic nitrogen supplements tried. The highest concentration of sabinene was $23.20 \mathrm{mg} / \mathrm{L}$, which was about 1.4 times as much as the lowest observed yeast extract.

\section{Effect of carbon source on sabinene production}

The source of carbon is the main feedstock in most fermentation media; therefore, finding efficient and cheap carbon source for sabinene production is important. In this study, mostly used carbon source glucose and glycerol were applied to investigate the effect of carbon source on sabinene production. As is shown in Figure 4B, the glycerol permitted a little higher sabinene production than glucose. The highest concentration of sabinene was $41.45 \mathrm{mg} / \mathrm{L}$, which was about 2.03 times as much as that of glucose as carbon source.

\section{Effect of induction temperature on sabinene production}

In this study, the induction temperatures of $25^{\circ} \mathrm{C}, 28^{\circ} \mathrm{C}$, $31^{\circ} \mathrm{C}, 34^{\circ} \mathrm{C}$ and $37^{\circ} \mathrm{C}$ were tried to increase sabinene production. As is shown in Figure $4 \mathrm{C}$, the maximum sabinene production was observed at $31^{\circ} \mathrm{C}$, at $71.50 \mathrm{mg} / \mathrm{L}$ with beef power as nitrogen source and glycerol as carbon source. It was about 2 times greater than that observed at $25^{\circ} \mathrm{C}$ $(36.12 \mathrm{mg} / \mathrm{L})$, and $37^{\circ} \mathrm{C}(36.19 \mathrm{mg} / \mathrm{L})$. The enzyme expression, cell growth and product formation should be balanced in a successful control of cultivation temperature. Because low temperatures decrease the inclusion bodies in genetically engineered $E$. coli, the activities of recombinant enzymes can be enhanced by low induction temperatures $\left(25^{\circ} \mathrm{C}\right.$ or $\left.30^{\circ} \mathrm{C}\right)[30,31]$. Hence, the optimal induction temperature for sabinene production was around $31^{\circ} \mathrm{C}$.

\section{Effect of inducer concentration on sabinene production}

To optimize the inducer concentration, various IPTG concentrations, ranging from $0.05 \mathrm{mM}$ to $1 \mathrm{mM}$, were tested. The production of sabinene reached a maximum of $82.18 \mathrm{mg} / \mathrm{L}$ at the IPTG concentration of $0.1 \mathrm{mM}$, which was about 2.45 times greater than those observed 


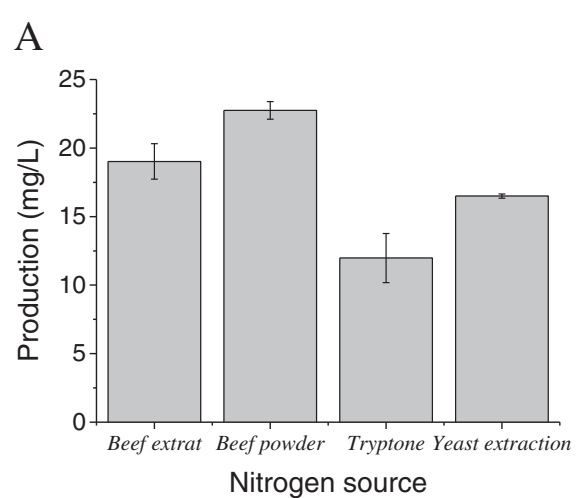

$\mathrm{C}$

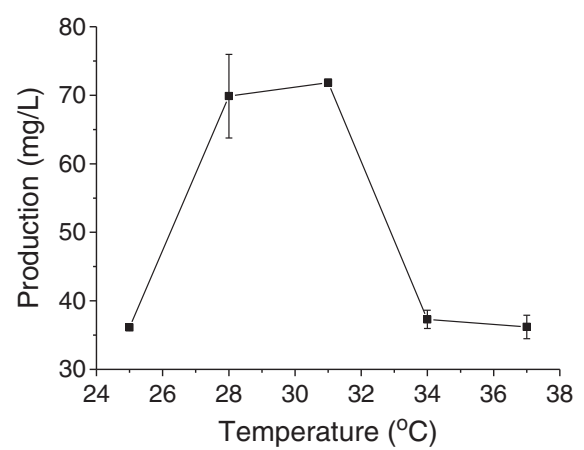

B

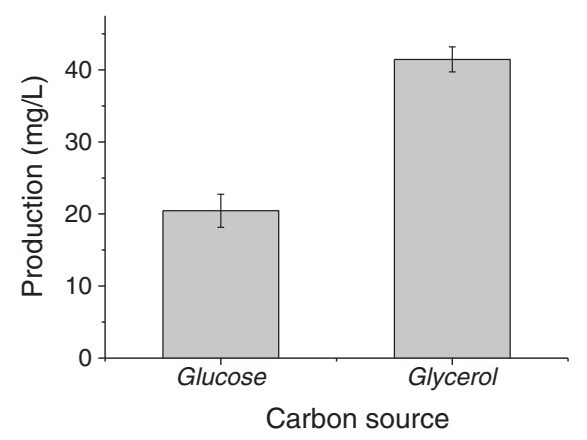

$\mathrm{D}$

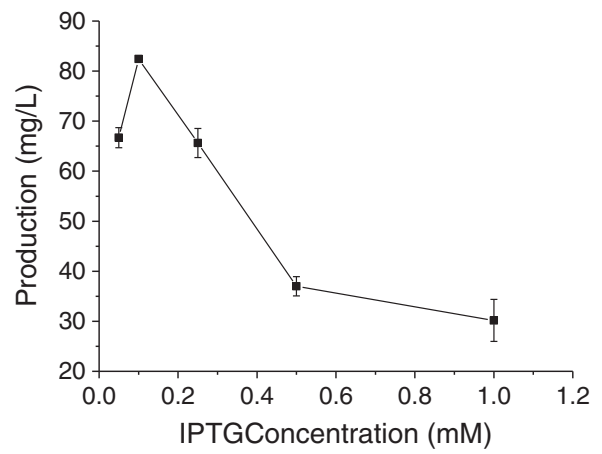

Figure 4 Effects of fermentation source and culture conditions on sabinene production by HB4. A: Effect of nitrogen sources on sabinene production; $\mathbf{B}$ : Effect of carbon sources on sabinene production; C: Effect of temperatures on sabinene production; $\mathbf{D}$ : Effect of the concentration of inducer on sabinene production. When $\mathrm{OD}_{600}$ reached 0.6-0.9, cultures were induced for $24 \mathrm{~h}$ using IPTG in shake-flasks. All the experiments were performed in triplicates. Optimized conditions: Nitrogen sources, beef power; Carbon source, glycerol; Temperature, $31^{\circ} \mathrm{C}$; IPTC concentration, $0.1 \mathrm{mM}$.

at $1.0 \mathrm{mM}(33.14 \mathrm{mg} / \mathrm{L})$. The level of IPTG used can be varied to adjust the extent of the metabolic burden imposed on the cell [32], which can result in reduced growth rates, cell yields, protein expression, and plasmid stability [33,34].

Therefore, the most suitable medium was using beef powder and glycerol as the nitrogen and carbon source, respectively, and optimal culture temperature for sabinene production was $31^{\circ} \mathrm{C}$ at the concentration of $0.1 \mathrm{mM}$ IPTG using the engineered strain HB4.

\section{Toxicity of commercial sabinene to $E$. coli}

Toxicity of sabinene to the overproducing organism plays an important role in the biosynthetic process. The commercial sabinene imparts toxicity to $E$. coli when added exogenously to the medium (Figure 5 ). The E. coli cell growth was comparable at $0 \mathrm{~g} / \mathrm{L}$ and up to $5 \mathrm{~g} / \mathrm{L}$ of exogenously added sabinene. Though the log phase of E. coli was prolonged with about $12 \mathrm{~h}$ by even $0.5 \mathrm{~g} / \mathrm{L}$ sabinene compared with the control, it can grow in $5 \mathrm{~g} / \mathrm{L}$ sabinene with inhibiting rates of $70 \%$ after inoculation and cultured for 36 hours (Figure 5). The results indicated that sabinene can be produced with the engineered $E$. coli, but the production tolerance cannot be neglected to get high titers.
The toxicity of products to the hosts is common in biosynthesis of biofuels and chemicals [3,35]. Expression of efflux pumps, heat shock proteins, membrane modifying proteins, and activation of general stress response genes all can improve tolerance of the hosts [2,3,36]. Furthermore, in situ product removal and membrane technology both can be used in the production of sabinene to get high titers [37].

\section{Fed-batch culture of the engineered strains}

Fed-batch fermentation was carried out using the engineered E. coli BL21(DE3) strain simultaneously harboring plasmids pHB7 and pTrcLower, in the optimized medium and culture conditions, to further determine the ability of the engineered strain to produce sabinene at high yield. Glycerol was added continuously when the initial carbon source was exhausted which was indicated by the sharp rise of DO. As is shown in Figure 6, sabinene production increased rapidly from $4 \mathrm{~h}$ to $20 \mathrm{~h}$ after induction. After the cultures were induced for $24 \mathrm{~h}$, sabinene reached a maximum concentration of $2.65 \mathrm{~g} / \mathrm{L}$ with an average productivity of $0.018 \mathrm{~g} / \mathrm{h} / \mathrm{g}$ dry cells, and the conversion efficiency of glycerol to sabinene (gram to gram) reached $3.49 \%$. 


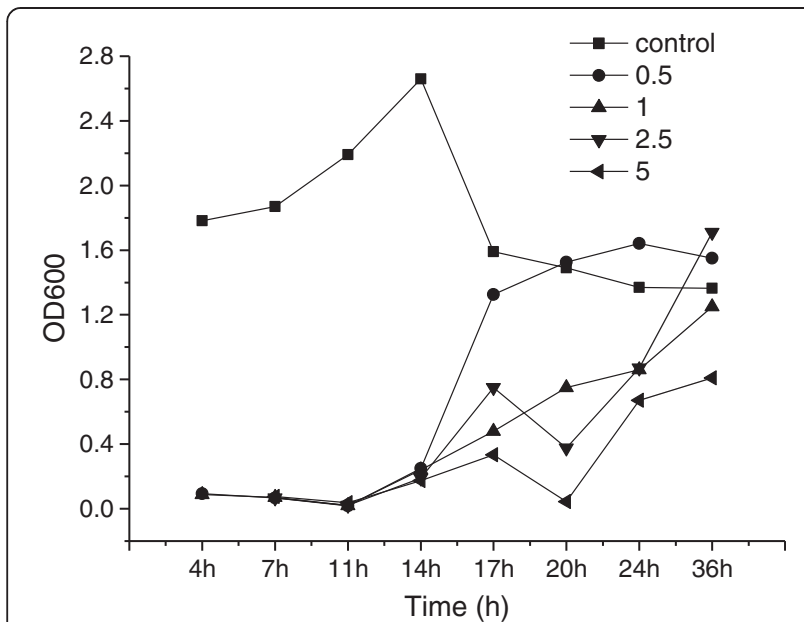

Figure 5 The growth of $E$. coli in LB medium with different concentration of commercial sabinene. The growth of the bacterial culture was determined by measuring the $\mathrm{OD}_{600}$ (the optical density at $600 \mathrm{~nm}$ ) with a spectrophotometer (Cary 50 UV-Vis, Varian) at 4 h, 7 h, 11 h, 14 h, 17 h, 20 h, 24 h and 36 h. The concentrations of sabinene were added to the LB medium as follows: $0 \mathrm{~g} / \mathrm{L}(\mathbf{\bullet}), 0.5 \mathrm{~g} / \mathrm{L}(\bullet), 1 \mathrm{~g} / \mathrm{L}(\mathbf{\Delta}), 2.5 \mathrm{~g} / \mathrm{L}(\mathbf{\nabla}), 5 \mathrm{~g} / \mathrm{L}(\boldsymbol{\triangleleft})$.

The maximum cell density of the engineered strain reached only about 14, four hours after being induced with IPTG, with a sabinene titer of no more than $0.5 \mathrm{~g} / \mathrm{L}$, which was rather low for the fed-batch fermentation of $E$. coli strains. The main reason for the low cell mass of $E$. coli strain may lie in the retardation of cell growth resulting from toxicity of the product, which was proved by the experiment of toxicity. Meanwhile, overexpression of many heterologous genes may be another reason. To resolve the above-mentioned problems, many

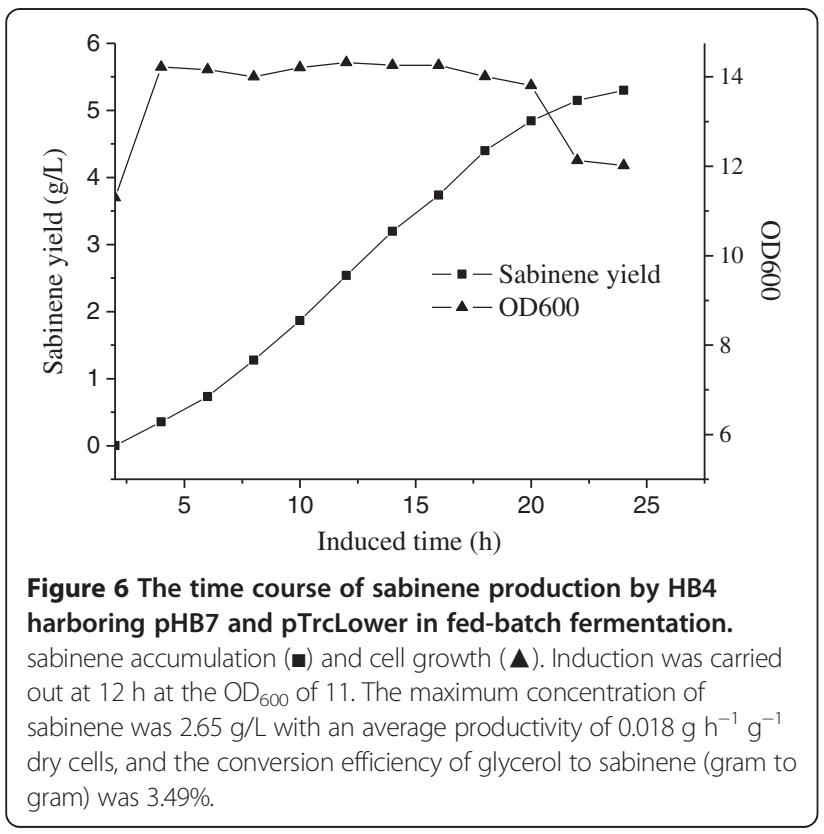

possible improvements can be achieved to enhance sabinene production. One approach is to optimize the fermentation process by increasing cell density to elevate the yield of products [38,39], using in situ product removal, membrane technology or dissociation of growth or cell mass formation from product formation to reduce the toxicity of sabinene [37]. Another approach is engineering of the host including: employing a chromosome integration technique to decrease the cell growth burden on the host that results from overexpression of heterologous genes [9], expression of efflux pumps, heat shock proteins, membrane modifying proteins, and activation of general stress response genes to improve tolerance of the host to sabinene $[2,3,36]$.

\section{Conclusions}

In this study, sabinene was significantly produced by assembling a biosynthetic pathway using the MEP or heterologous MVA pathway combining the GPP and sabinene synthase genes in an engineered E. coli strain. Subsequently, the culture medium and process conditions were optimized to enhance sabinene production. Finally, we also evaluated the fed-batch fermentation of sabinene using the optimized culture medium and process conditions, sabinene reached a maximum concentration of $2.65 \mathrm{~g} / \mathrm{L}$ with an average productivity of $0.018 \mathrm{~g} / \mathrm{h} / \mathrm{g}$ dry cells, and the conversion efficiency of glycerol to sabinene (gram to gram) reached $3.49 \%$. As far as we know, this is the first report of biosynthesis of sabinene using an engineered $E$. coli strain with the renewable carbon source as feedstock. Therefore, a green and sustainable production strategy has been provided for sabinene from renewable sources in E. coli.

\section{Methods and materials}

\section{Plasmids, bacterial strains, and growth conditions}

All plasmids and strains used in this study are listed in Table 1. E. coli BL21(DE3) (Invitrogen, Carlsbad, CA) was used as the host to overexpress proteins and produce sabinene. Cultures were grown aerobically at $37^{\circ} \mathrm{C}$ in Luria Broth (tryptone $10 \mathrm{~g} / \mathrm{L}, \mathrm{NaCl} 10 \mathrm{~g} / \mathrm{L}$, and yeast extract $5 \mathrm{~g} / \mathrm{L}$ at $\mathrm{pH}$ 7.0-7.4). For initial production of sabinene experiments in shake-flasks, strains were grown in a medium (initial production medium) [40] consisting of the following: $20 \mathrm{~g} / \mathrm{L}$ glucose, $9.8 \mathrm{~g} / \mathrm{L} \mathrm{K} \mathrm{HPO}_{4}, 5 \mathrm{~g} / \mathrm{L}$ beef extract, $0.3 \mathrm{~g} / \mathrm{L}$ ferric ammonium citrate, $2.1 \mathrm{~g} / \mathrm{L}$ citric acid monohydrate, $0.06 \mathrm{~g} / \mathrm{L} \mathrm{MgSO}_{4}$ and $1 \mathrm{ml} / \mathrm{L}$ of trace element solution, which included $\left(\mathrm{NH}_{4}\right)_{6} \mathrm{Mo}_{7} \mathrm{O}_{24} \cdot 4 \mathrm{H}_{2} \mathrm{O} 0.37 \mathrm{~g} / \mathrm{L}$, $\mathrm{ZnSO}_{4} \cdot 7 \mathrm{H}_{2} \mathrm{O} 0.29 \mathrm{~g} / \mathrm{L}, \mathrm{H}_{3} \mathrm{BO}_{4} 2.47 \mathrm{~g} / \mathrm{L}, \mathrm{CuSO}_{4} \cdot 5 \mathrm{H}_{2} \mathrm{O}$ $0.25 \mathrm{~g} / \mathrm{L}$, and $\mathrm{MnCl}_{2} \cdot 4 \mathrm{H}_{2} \mathrm{O} 1.58 \mathrm{~g} / \mathrm{L}$. Ampicillin (Amp, $100 \mu \mathrm{g} / \mathrm{mL})$ and chloramphenicol $(\mathrm{Cm}, 34 \mu \mathrm{g} / \mathrm{mL})$ was added if necessary.

Biosensor equipped with glucose oxidase membrane electrodes (Shandong Academy of Sciences, Jinan, China) was applied to determine the concentration of glucose. 
Table 1 Plasmids and strains used in this study

\begin{tabular}{|c|c|c|}
\hline Name & Relevant characteristics & References \\
\hline \multicolumn{3}{|l|}{ Plasmids } \\
\hline pACYCDuet-1 & P15A origin; $\mathrm{Cm}^{\mathrm{R}} ; \mathrm{P}_{\mathrm{T}}$ & Novagen \\
\hline pTrcHis2B & ColE1 origin; $A m p^{R} ; P_{\text {trc }}$ & Invitrogen \\
\hline $\mathrm{pGH}$ & pUC origin; $A m p^{R} ; P_{T 7}$ & Generay \\
\hline pTrcLower & ColE1 origin; $\mathrm{Amp}^{\mathrm{R}}$; $\mathrm{P}_{\mathrm{tr}::}$ ERG12-ERG8-ERG19-ID/1 & [42] \\
\hline pHB1 & P15A origin; $\mathrm{Cm}^{\mathrm{R}} ; \mathrm{P}_{\mathrm{T} 7:}: \mathrm{SabS1}$ & This work \\
\hline pHB2 & P15A origin; $\mathrm{Cm}^{\mathrm{R}} ; \mathrm{P}_{\mathrm{T} 7: 1 / \mathrm{sp} A}$ & This work \\
\hline pHB3 & $\mathrm{P} 15 \mathrm{~A}$ origin; $\mathrm{Cm}^{\mathrm{R}} ; \mathrm{P}_{\mathrm{T} 7 .: I s p A-S a b S 1}$ & This work \\
\hline pHB4 & P15A origin; $\mathrm{Cm}^{\mathrm{R}} ; \mathrm{P}_{\mathrm{T} 7::}$ GPPS2 & This work \\
\hline pHB5 & P15A origin; $\mathrm{Cm}^{\mathrm{R}} ; \mathrm{P}_{\mathrm{T} 7 .:}$ GPPS2-SabS1 & This work \\
\hline pHB6 & P15A origin; $\mathrm{Cm}^{\mathrm{R}} ; \mathrm{P}_{\mathrm{T} 7: .: \text { mvaE-GPPS2-SabS1 }}$ & \\
\hline pHB7 & P15A origin; $\mathrm{Cm}^{\mathrm{R}} ; \mathrm{P}_{\text {T7 }:: m v a E-m v a S-G P P S 2-S a b S 1}$ & This work \\
\hline \multicolumn{3}{|l|}{ Strains } \\
\hline E. coli BL21(DE3) & E. coli B dcm ompT hsdS(rB- $\left.{ }^{-} \mathrm{mB}^{-}\right) \mathrm{gal}$ & Takara \\
\hline E. coli DH5a & deoR, recA1, endA1, hsdR17(rk, mk ${ }^{+}$, phoA, supE44, $\lambda$-, thi'1, gyrA96, relA1 & Invitrogen \\
\hline Saccharomyces cerevisiae & Type strain & ATCC 204508 \\
\hline HB1 & E. coli BL21(DE3) harboring pHB1 & This work \\
\hline HB2 & E. coli BL21(DE3) harboring pHB3 & This work \\
\hline HB3 & E. coli BL21(DE3) harboring pHB5 & This work \\
\hline HB4 & E. coli BL21(DE3) harboring pHB7 and pTrcLower & This work \\
\hline
\end{tabular}

\section{Plasmid construction}

The experiments were carried out according to standard protocols [41]. Polymerase chain reaction (PCR) was performed using Pfu DNA polymerase (TaKaRa, Dalian, China) according to the manufacturer's instructions.

\section{Construction of plasmids for GPP synthase screening}

E. coli BL21(DE3) genomic DNA was amplified as a template to obtain the IspA gene by PCR using the primers IspA-F and IspA-R (Table 2). The IspA gene fragment was digested using $B g l$ II and Nde I, and subsequently cloned into the corresponding sites of the vector pACYCDuet-1 to create pHB2 (Table 1). The SabS1 gene fragment (mentioned blow) was obtained by digestion of $\mathrm{pGH} / \mathrm{Pt} 30$ with $B g l$ II and Xho I and was introduced into the corresponding sites of pHB2 to create pHB3.
The geranyl diphosphate synthase gene (GPPS2, GenBank No. AF513112) from Abies grandis and sabinene synthase gene (SabS1, GenBank No. ABH07678.1) from Salvia pomifera were analyzed by online software (http://www. genscript.com/cgi-bin/tools/rare_codon_analysis) and optimized to the preferred codon usage of E. coli (http://www. jcat.de/). The codon-optimized GPPS2 gene and SabS1 gene were synthesized by Generay Company with plasmid pGH as the vector (pGH-GPPS2 and pGH-SabS1). The SabS1 gene fragment was obtained by digestion of pGHSabS1 with Bgl II and Xho I and then cloned into the corresponding sites of pACYCDuet- 1 to create pHB1. The GPPS 2 gene fragment was obtained by digestion of pGH-GPPS 2 with Nde I and $B g l$ II and then cloned into the corresponding sites of pACYCDuet-1 to create pHB4. The SabS1 gene fragment was obtained by

Table 2 Primers used in this study

\begin{tabular}{|c|c|}
\hline Name & Sequence $\left(5^{\prime} \rightarrow 3^{\prime}\right)$ \\
\hline IspA-F & GGGAATTCCATATGATGGACTTTCCGCAGCAACTC \\
\hline IspA-R & GGAAGATCTITATTATTACGCTGGATGATGT \\
\hline mvaE-F & CATGCCATGGAGGAGGTAAAAAAACATGAAAACAGTAGTTATTATTGATGC \\
\hline mvaE-R & CGCGGATCCTTATTGITTCTTAAATCATITAAAATAGCGCGGA TCCTTATTGTITCTTAAATCATTAAAAATAG \\
\hline mvaS-F & CCAGAGCTCAGGAGGTAAAAAAACATGACAATTGGGATTGATAAAATTA \\
\hline mvaS-R & CAACTGCAGTTAGTITCGATAAGAGCGAACG \\
\hline
\end{tabular}


digesting pGH-SabS1 with $B g l$ II and Xho I and was ligated into the corresponding sites of pHB4 to construct pHB5.

\section{Construction of plasmids for the whole pathway of sabinene synthesis}

As mentioned above, E. coli BL21(DE3) has its native MEP pathway to form IPP and DMAPP. Therefore, the MEP pathway for sabinene synthesis was constructed by harboring the plasmid pHB1 to introduce the exogenous sabinene synthase. Furthermore, to enhance the metabolic flux into GPP by catalyzing the conversion of DMAPP and IPP, the GPP synthase (IspA or GPPS2) was overexpressed or introduced.

E. coli BL21(DE3) harboring pHB7 and pTrcLower was constructed to form the MVA pathway for sabinene synthesis. The mvaE (Genbank: AF290092) was amplified with the primer mvaE-F and mvaE-R from genomic DNA of Enterococcus faecalis (ATCC 700802D-5) and then cloned into pHB5 and with restriction enzymes Nco I and Bam HI, creating pHB6. The mvaS (Genbank: AF290092) was amplified from genomic DNA of E. faecalis (ATCC 700802D-5) with the primer mvaS-F and mvaS-R and cloned into pHB6 and with restriction enzymes Sac I and Pst I, creating pHB7. The ERG12, ERG8, ERG19 and IDI1 genes from S. cerevisiae (ATCC 204508) were cloned into pTrcHis2B (Invitrogen, Carlsbad, CA) using a method of successive hybridization to yield pTrcLower [42].

\section{Characterization of sabinene by GC-MS}

The E. coli strain was inoculated in $50 \mathrm{ml}$ of fermentation medium containing $34 \mu \mathrm{g} / \mathrm{mL} \mathrm{Cm}$ and then cultured at $37^{\circ} \mathrm{C}$ with shaking at $180 \mathrm{rpm}$. When the $\mathrm{OD}_{600}$ of the bacterial culture reached 0.6-0.9, the cells were induced by IPTG at a final concentration of $0.25 \mathrm{mM}$ for $24 \mathrm{~h}$. Then, the off-gas samples were taken from the headspace of the sealed cultures and analyzed by GC-MS.

Products characterization was carried out by capillary GC-MS using an Agilent 5975C system chromatograph. A HP-INNOWAX capillary column $(30 \mathrm{~m} \times 0.25 \mathrm{~mm} \times$ $0.25 \mu \mathrm{m}$, Agilent, Palo Alto, CA, USA) was used, with helium as the carrier gas at a flow rate of $1 \mathrm{ml} \mathrm{min}^{-1}$. The following oven temperature program was carried out: $40^{\circ} \mathrm{C}$ for $1 \mathrm{~min}$, increase of $4^{\circ} \mathrm{C} / \mathrm{min}$ to $70^{\circ} \mathrm{C}$, then programmed from $70^{\circ} \mathrm{C}$ to $250^{\circ} \mathrm{C}$ at $25^{\circ} \mathrm{C} / \mathrm{min}$, where it was held for $5 \mathrm{~min}$. The injector temperature was maintained at $250^{\circ} \mathrm{C}$; ion source temperature $230^{\circ} \mathrm{C}$; EI $70 \mathrm{eV}$; mass range $35-300 \mathrm{~m} / \mathrm{z}$. suitable amount of samples were injected in split injection mode with a 20:1 split ratio. Peak identification was based on the relative retention time and total ion mass spectral comparison with the external standard.
Quantification of sabinene by gas chromatography (GC) The different strains were inoculated in $50 \mathrm{ml}$ of fermentation medium containing $34 \mu \mathrm{g} / \mathrm{mL} \mathrm{Cm}$ and/or $100 \mu \mathrm{g} / \mathrm{mL}$ Amp and then cultured under the conditions mentioned above. Finally, the off-gas samples were taken from the headspace of the sealed cultures and analyzed by GC.

The GC analysis was performed on an Agilent 7890A equipped with a flame ionization detector (FID). The separation of sabinene was performed using an HPINNOWAX column $(25 \mathrm{~m} \times 250 \mu \mathrm{m} \times 0.2 \mu \mathrm{m})$. The linear velocity was $1 \mathrm{ml} / \mathrm{min}$ with $\mathrm{N}_{2}$ as carrier gas. The oven temperature was initially held at $50^{\circ} \mathrm{C}$ for $1 \mathrm{~min}$, increased at $5^{\circ} \mathrm{C} / \mathrm{min}$ to $100^{\circ} \mathrm{C}$ to $250^{\circ} \mathrm{C}$, and finally held at $250^{\circ} \mathrm{C}$ for $5 \mathrm{~min}$. The temperatures of injector and detector were held at $250^{\circ} \mathrm{C}$ and $260^{\circ} \mathrm{C}$, respectively. The peak area was converted into sabinene concentration in comparison with a standard curve plotted with a set of known concentrations of sabinene which was bought from Sigma-Aldrich.

\section{Optimization of fermentation medium and process}

Optimization of fermentation medium was performed in shake-flask experiments in triplicate series of $600 \mathrm{ml}$ sealed shake flasks containing $50 \mathrm{ml}$ of fermentation medium incubated with the strain HB4. Amp $(100 \mu \mathrm{g} /$ $\mathrm{mL})$ and $\mathrm{Cm}(34 \mu \mathrm{g} / \mathrm{mL})$ were added when it was necessary. E. coli strains were cultured in the broth for initial production of sabinene and incubated in a gyratory shaker incubator at $37^{\circ} \mathrm{C}$ and $180 \mathrm{rpm}$. When the $\mathrm{OD}_{600}$ reached 0.6-0.9 [40], IPTG was added to a final concentration of $0.25 \mathrm{mM}$, and the culture was further incubated at $30^{\circ} \mathrm{C}$ for $24 \mathrm{~h}$. Then, $1 \mathrm{ml}$ of gas sample from the headspace of the sealed cultures was quantified as described previously [43]. Concentrations of synthesized sabinene were calculated by converting the GC peak area into milligrams of sabinene via a calibration curve.

\section{Effect of organic nitrogen source}

The shake-flask cultures were incubated in initial medium with different organic nitrogen sources $(5 \mathrm{~g} / \mathrm{L})$ : beef extract (solarbio), beef powder (MDBio, Inc), tryptone (Beijing AoBoXing Bio-Tech Co., Ltd) or yeast extract powder (Beijing AoBoXing Bio-Tech Co., Ltd)) at the above-mentioned culture conditions, and the sabinene products were detected.

\section{Effect of carbon source}

Carbon source is the main feedstock in fermentation. Therefore, the commonly used carbon sources (glucose and glycerol, $20 \mathrm{~g} / \mathrm{L}$ ) were screened in shake-flask with the nitrogen-optimized initial medium, at the abovementioned culture conditions. 


\section{Effect of induction temperature}

The E. coli strain was inoculated in $50 \mathrm{ml}$ of optimized fermentation medium and cultured with shaking at $180 \mathrm{rpm}$. The shake-flask cultures were incubated at different induction temperatures $\left(25^{\circ} \mathrm{C}, 28^{\circ} \mathrm{C}, 31^{\circ} \mathrm{C}, 34^{\circ} \mathrm{C}\right.$ or $\left.37^{\circ} \mathrm{C}\right)$, when the $\mathrm{OD}_{600}$ of the bacterial culture reached $0.6-0.9$, for $24 \mathrm{~h}$ in a final concentration of $0.5 \mathrm{mM}$, and the sabinene products were quantified.

\section{Effect of IPTG concentration}

The shake-flask culture was incubated in different inducer (IPTG) concentrations (0.05 mM, $0.1 \mathrm{mM}, 0.25 \mathrm{mM}$, $0.5 \mathrm{mM}$ or $1 \mathrm{mM}$ ) at the optimized temperature for $24 \mathrm{~h}$, and the sabinene products were measured.

\section{Toxicity of commercial sabinene to $E$. coli}

The sealed shake-flask culture was incubated in $50 \mathrm{ml}$ of optimized fermentation medium and cultured with shaking at $180 \mathrm{rpm}$ at a temperature of $31^{\circ} \mathrm{C}$, with different concentration of commercial sabinene $(0.5 \mathrm{~g} / \mathrm{L}, 1 \mathrm{~g} / \mathrm{L}$, $2.5 \mathrm{~g} / \mathrm{L}$, and $5 \mathrm{~g} / \mathrm{L})$. Meanwhile, the growth of the bacterial culture was determined by measuring the $\mathrm{OD}_{600}$ (the optical density at $600 \mathrm{~nm}$ ) with a spectrophotometer (Cary $50 \mathrm{UV}-$ Vis, Varian) at $4 \mathrm{~h}, 7 \mathrm{~h}, 11 \mathrm{~h}, 14 \mathrm{~h}, 17 \mathrm{~h}, 20 \mathrm{~h}, 24 \mathrm{~h}$ and $36 \mathrm{~h}$. The inhibition rate (IR) was calculated by the following equation:

$$
\mathrm{IR}=\left(1-O D_{600 s} / O D_{600 C}\right) \times 100 \%
$$

Where IR = Inhibition rate $(100 \%) ; O D_{600 s}=\mathrm{OD}_{600}$ of sample; $O D_{600 C}=\mathrm{OD}_{600}$ of control at the same time as the sample.

\section{Fed-batch fermentation}

The strain HB4 harboring pHB7 and pTrcLower was inoculated to $5 \mathrm{ml}$ of LB medium (Amp $100 \mu \mathrm{g} / \mathrm{mL}, \mathrm{Cm} 34 \mu \mathrm{g}$ / $\mathrm{mL}, 37^{\circ} \mathrm{C}, 180 \mathrm{rpm}$ ), and then $100 \mathrm{ml}$ fresh $\mathrm{LB}$ medium with corresponding antibiotics was inoculated with the $5 \mathrm{ml}$ overnight cultures, which were used to inoculate a $5-\mathrm{L}$ fermentor (BIOSTAT Bplus MO5L, Sartorius, Germany) containing $2 \mathrm{~L}$ of optimized fermentation medium (Amp $100 \mu \mathrm{g} / \mathrm{mL}, \mathrm{Cm} 34 \mu \mathrm{g} / \mathrm{mL}$ ). The temperature was maintained at $37^{\circ} \mathrm{C}$ firstly, and then $30^{\circ} \mathrm{C}$ after induced. The $\mathrm{pH}$ was maintained at 7.0 via automated addition of ammonia, and foam development was prohibited with 1\% Antifoam 204. The stirring speed was first set at $400 \mathrm{rpm}$ and then linked to the dissolved oxygen (DO) concentration to maintain a $20 \%$ saturation of DO, the flow velocity of air was $1.5 \mathrm{~L} / \mathrm{min}$. The expression of heterogenous genes for sabinene production was initiated at an $\mathrm{OD}_{600}$ of 11 by adding IPTG at a final concentration of $0.15 \mathrm{mM}$, and IPTG was supplemented every $8 \mathrm{~h}$. During the course of fermentation, the $40 \%$ glycerol was fed at a rate $4 \mathrm{~g} / \mathrm{L} / \mathrm{h}$. Then, sabinene accumulation was measured every $60 \mathrm{~min}$ by $\mathrm{GC}$ as described above. Meanwhile, the growth of the bacterial culture was determined by measuring the $\mathrm{OD}_{600}$ with the spectrophotometer, and the dry cell weight was calculated according to the coefficient (one $\mathrm{OD}_{600}$ unit corresponded to $0.43 \mathrm{~g} / \mathrm{L}$ of dry cell weight).

The specific productivity was calculated by the following equation [44].

$$
\mathbf{Q}_{s}=\frac{s_{1}-s_{0}}{t_{1}-t_{\mathbf{0}}} \times \frac{2}{x_{\mathbf{1}}+x_{\mathbf{0}}}
$$

Where $\mathrm{Q}_{\mathrm{s}}=$ specific production rate $(\mathrm{g} / \mathrm{h} / \mathrm{g}$ dry cells); $\mathrm{s}=$ sabinene concentration $(\mathrm{g} / \mathrm{L}) ; \mathrm{t}=$ cultivation time $(\mathrm{h})$, and $\mathrm{x}=$ biomass $(\mathrm{g} / \mathrm{L})$.

Conversion efficiency (gram to gram) of glycerol to sabinene was calculated by the following equation:

$$
\mathrm{Y}=G_{s} / G_{g} \times 100 \%
$$

Where $\mathrm{Y}=$ conversion efficiency (gram to gram, 100\%); $G_{s}=$ weight of sabinene $(\mathrm{g}) ; G_{g}=$ weight of glycerol $(\mathrm{g})$.

\section{Abbreviations}

Amp: Ampicillin; Cm: Chloramphenicol; DMAPP: Dimethylallyl pyrophosphate; IPP: Isopentenyl pyrophosphate; GPP: Geranyl diphosphate; GPPS: Geranyl diphosphate synthase; MVA: Mevalonate; MEP: Methylerythritol 4-phosphate; IPTG: Isopropyl $\beta$-D-thiogalactoside; PCR: Polymerase chain reaction; GC: Gas chromatography; GC-MS: Gas chromatography-mass spectrography; DO: Dissolved oxygen.

\section{Competing interests}

The authors declare that they have no competing interests.

\section{Authors' contributions}

MX and JY developed the idea for the study, and helped to revise the manuscript. $\mathrm{HZ}$ designed the research, did the literature review and prepared the manuscript. $\mathrm{HZ}, \mathrm{QL}$, and JY did experiments, plasmid construction, strain cultivation, Fed-Batch fermentation and product detection. All authors read and approved the final manuscript.

\section{Acknowledgements}

We greatly appreciate the financially support from the Qingdao Applied Basic Research Program (No. 12-1-4-9-(3)-jch), National Key Technology R\&D Program (No. 2012BAD32B06), National High Technology Research and Development Program of China (863 Program, No. SS2013AA050703-2), National Natural Science Foundation of China (No. 21202179, 21376255), Knowledge Innovation Program of the Chinese Academy of Sciences (Y112131105).

\section{Author details}

${ }^{1}$ CAS Key Laboratory of Biobased Materials, Qingdao Institute of Bioenergy and Bioprocess Technology, Chinese Academy of Sciences, No.189 Songling Road, Qingdao, Laoshan District 266101, China. ${ }^{2}$ College of Food Science,

Sichuan Agricultural University, Yaan 625014, China.

Received: 17 October 2013 Accepted: 3 February 2014

Published: 10 February 2014

\section{References}

1. Peralta-Yahya PP, Keasling JD: Advanced biofuel production in microbes. Biotech J 2010, 5:147-162.

2. Piper PW: The heat shock and ethanol stress responses of yeast exhibit extensive similarity and functional overlap. FEMS Microbiol Lett 1995, 134:121-127.

3. Jiang $X$, Zhang $H$, Yang J, Liu M, Feng H, Liu X, Cao Y, Feng D, Xian M: Induction of gene expression in bacteria at optimal growth temperatures. Appl Microbiol Biotechnol 2013, 97(12):5423-5431. 
4. Behr A, Johnen L: Myrcene as a natural base chemical in sustainable chemistry: a critical review. ChemSusChem 2009, 2:1072-1095.

5. Brown HC, Ramachandran PV: Asymmetric reduction with chiral organoboranes based on. alpha.-pinene. Accounts Chem Res 1992, 25:16-24

6. Kirby J, Keasling JD: Biosynthesis of plant isoprenoids: perspectives for microbial engineering. Annu Rev Plant Biol 2009, 60:335-355.

7. Ryder JA: Patent US 7,935,156 B2 - Jet fuel compositions and methods of making and using same; 2011.

8. Rude MA, Schirmer A: New microbial fuels: a biotech perspective. Curr Opin Microbiol 2009, 12:274-281.

9. Chen H-T, Lin M-S, Hou S-Y: Multiple-copy-gene integration on chromosome of Escherichia coli for beta-galactosidase production. Korean J Chem Eng 2008, 25:1082-1087.

10. Steinbüchel A: Production of rubber-like polymers by microorganisms. Curr Opini Microbiol 2003, 6:261-270.

11. Reiling KK, Yoshikuni Y, Martin VJJ, Newman J, Bohlmann J, Keasling JD: Mono and diterpene production in Escherichia coli. Biotechnol Bioeng 2004, 87:200-212.

12. Carter OA, Peters RJ, Croteau R: Monoterpene biosynthesis pathway construction in Escherichia coli. Phytochemistry 2003, 64:425-433.

13. Peralta-Yahy PP, Ouellet M, Chan R, Mukhopadhyay A, Keasling JD, Lee TS: Identification and microbial production of a terpene-based advanced biofuel. Nat commun 2011, 2:483.

14. Bokinsky G, Peralta-Yahya PP, George A, Holmes BM, Steen EJ, Dietrich J, Lee TS, Tullman-Ercek D, Voigt CA, Simmons BA, Keasling JD: Synthesis of three advanced biofuels from ionic liquid-pretreated switchgrass using engineered Escherichia coli. Proc Natl Acad Sci U S A 2011, 108:19949-19954.

15. Chang MCY, Keasling JD: Production of isoprenoid pharmaceuticals by engineered microbes. Nat Chem Biol 2006, 2:674-681.

16. Singh SK, Strobel GA, Knighton B, Geary B, Sears J, Ezra D: An endophytic Phomopsis $s p$. possessing bioactivity and fuel potential with its volatile organic compounds. Microb Ecol 2011, 61:729-739.

17. Schmidt-Dannert C, Umeno D, Arnold FH: Molecular breeding of carotenoid biosynthetic pathways. Nat Biotechnol 2000, 18:750-753.

18. Clomburg JM, Gonzalez R: Biofuel production in Escherichia coli: the role of metabolic engineering and synthetic biology. Appl Microbiol Biotechnol 2010, 86:419-434.

19. Leonard E, Lim K-H, Saw P-N, Koffas MAG: Engineering central metabolic pathways for high-level flavonoid production in Escherichia coli. Appl Environ Microbiol 2007, 73:3877-3886.

20. Burke C, Croteau R: Geranyl diphosphate synthase from Abies grandis: cDNA isolation, functional expression, and characterization. Arch Biochem Biophys 2002, 405:130-136.

21. Yan YC, Liao J: Engineering metabolic systems for production of advanced fuels. J Ind Microbiol Biotechnol 2009, 36:471-479.

22. Fujisaki S, Nishino T, Katsuki H: Isoprenoid synthesis in Escherichia coli. Separation and partial purification of four enzymes involved in the synthesis. J Biochem 1986, 99:1327-1337.

23. Yang J, Xian M, Su S, Zhao G, Nie Q, Jiang X, Yanning Z, Liu W: Enhancing production of bio-isoprene using hybrid MVA pathway and isoprene synthase in E. coli. PloS One 2012, 7:e33509.

24. Martin VJJ, Pitera DJ, Withers ST, Newman JD, Keasling JD: Engineering a mevalonate pathway in Escherichia coli for production of terpenoids. Nat Biotechnol 2003, 21:796-802.

25. Zhao Y, Yang J, Qin B, Li Y, Sun Y, Su S, Xian M: Biosynthesis of isoprene in Escherichia coli via methylerythritol phosphate (MEP) pathway. Appl Microbiol Biotechnol 2011, 90:1915-19922.

26. Schmidt FR: Optimization and scale up of industrial fermentation processes. Appl Microbiol Biotechnol 2005, 68:425-435.

27. Ahamad M, Panda B, Javed S, Ali M: Production of mevastatin by solid-state fermentation using wheat bran as substrate. Res J Microbiol 2006, 1:443-447.

28. Alexeeva YV, Ivanova EP, Bakunina IY, Zvaygintseva TN, Mikhailov W: Optimization of glycosidases production by Pseudoalteromonas issachenkonii KMM 3549T. Lett Appl Microbiol 2002, 35:343-346.

29. Torija MJ, Beltran G, Novo M, Poblet M, Rozès N, Guillamón JM, Mas A: Effect of the nitrogen source on the fatty acid composition of Saccharomyces cerevisiae. Food Microbiol 2003, 20:255-258.

30. Hunke S, Betton J-M: Temperature effect on inclusion body formation and stress response in the periplasm of Escherichia coli. Mol Microbiol 2003, 50:1579-1589.
31. Groota NS, Ventura S: Effect of temperature on protein quality in bacterial inclusion bodies. FEBS Lett 2006, 580:6471-6476.

32. Donovan R, Robinson C, Glick B: Review: optimizing inducer and culture conditions for expression of foreign proteins under the control of thelac promoter. J Ind Microbiol Biotechnol 1996, 16:145-154.

33. Bentley WE, Mirjalili N, Andersen DC, Davis RH, Kompala DS: Plasmidencoded protein: the principal factor in the "metabolic burden" associated with recombinant bacteria. Biotechnol Bioeng 1990, 35:668-681.

34. Glick BR: Metabolic load and heterologous gene expression. Biotechnol Adv 1995, 13:247-261.

35. Dunlop MJ: Engineering microbes for tolerance to next-generation biofuels. Biotechnol Biofuels 2011, 4:32

36. Holtwick R, Meinhardt F, Keweloh H: cis-trans isomerization of unsaturated fatty acids: cloning and sequencing of the cti gene from Pseudomonas putida P8. Appl Environ Microbiol 1997, 63:4292-4297.

37. Ataei SA, Vasheghani-Farahani E: In situ separation of lactic acid from fermentation broth using ion exchange resins. J Ind Microbiol Biotechnol 2008, 35:1229-1233.

38. Wang D, Li Q, Song Z, Zhou W, Su Z, Xing J: High cell density fermentation via a metabolically engineered Escherichia coli for the enhanced production of succinic acid. J Chem Technol Biotechnol 2011, 86:512-518.

39. Chen N, Huang J, Feng Z, Yu L, Xu Q, Wen T: Optimization of fermentation conditions for the biosynthesis of L-Threonine by Escherichia coli. Appl Biochem Biotechnol 2009, 158:595-604.

40. Yang J, Zhao G, Sun Y, Zheng Y, Jiang X, Liu W, Xian M: Bio-isoprene production using exogenous MVA pathway and isoprene synthase in Escherichia coli. Bioresour Technol 2012, 104:642-647.

41. Sambrook J, Russell DW: Molecular cloning: a laboratory manual. 3rd edition. Cold Spring Harbor: Cold Spring Harbor Laboratory Press; 2001.

42. Jiang $X$, Yang J, Zhang H, Zou H, Wang C, Xian M: In vtro assembly of multiple DNA fragments using successive hybridization. PLOS ONE 2012, 7:e30267.

43. Kolb B: Headspace sampling with capillary columns. J Chromatogr A 1999, 842:163-205.

44. Tashiro Y, Takeda K, Kobayashi G, Sonomoto K, Ishizaki A, Yoshino S: High butanol production by Clostridium saccharoperbutylacetonicum N1-4 in fed-batch culture with $\mathrm{pH}$-stat continuous butyric acid and glucose feeding method. J Biosci Bioeng 2004, 98:263-268.

doi:10.1186/1475-2859-13-20

Cite this article as: Zhang et al: Microbial production of sabinene-a new terpene-based precursor of advanced biofuel. Microbial Cell Factories 2014 13:20.

\section{Submit your next manuscript to BioMed Central and take full advantage of:}

- Convenient online submission

- Thorough peer review

- No space constraints or color figure charges

- Immediate publication on acceptance

- Inclusion in PubMed, CAS, Scopus and Google Scholar

- Research which is freely available for redistribution 